\title{
The surgeon's autoclave
}

\author{
J. W. HOWIE \\ From the Bacteriology Department of the University and Western Infirmary of Glasgow
}

This difficult, costly, and complex piece of engineering occupies a central place in what is aptly described as the aseptic ritual. The autoclave is intended to guarantee the sterility of articles which have been put into it by exposing them to steam at a greater than atmospheric pressure and therefore at a temperature over $100^{\circ} \mathrm{C}$. $\left(212^{\circ} \mathrm{F}\right.$.) and usually between $121^{\circ} \mathrm{C}$. $\left(250^{\circ} \mathrm{F}\right.$.) and $134^{\circ} \mathrm{C}$. $\left(274^{\circ} \mathrm{F}\right.$.). Within the past five years surgeons' autoclaves in Great Britain have been the subject of critical reports and investigations which clearly revealed that a great many of the autoclaves could not be relied upon to effect sterilization as they were being used (see, for example, Bowie, 1955; Howie and Timbury, 1956; Scott, 1957; Magee and Oakes, 1958; Nuffield Trust Report, 1958; Medical Research Council Report, 1959; and Wells and Whitwell, 1960). From the same work and that of others (see Bowie, 1958a and b; Alder and Gillespie, 1957; Knox and Penikett, 1958; Penikett, Rowe, and Robson, 1958; Rice, 1958; 1960; Medical Research Council Report, 1960) recommendations emerged about better methods for the construction, installation, maintenance, and operation of autoclaves. These communications were received with general interest, and the object of the present paper is to set down what seem to be the main points of all this activity and to emphasize a few principles. If these principles are not understood and acted upon we shall do no more than exchange one form of meaningless ritual for another. The necessity is to devise and ensure the continuous exercise of an effective process.

\section{NEED AN AUTOCLAVE STERILIZE?}

Sometimes the question is asked whether autoclaves matter a great deal in the prevention of postoperative wound infection. An answer to this variety of agnosticism can hardly be made in quantitative terms from surgical practice in man as a moment's humane reflection will surely reveal; but the answer is not less emphatic because it cannot be expressed in figures. If an article is labelled or may credibly be presumed to be 'sterile', a surgeon may use it with a clear conscience. But if it may be labelled only 'probably sterile,' dare the surgeon accept it? What will be the effect on his medical and nursing colleagues if he does? Will the sister's grip of the aseptic ritual in her theatre remain effective? We all know of horror stories without a moral: of the autoclave that proved acceptable for seven years although no steam ever entered its chamber, but only its jacket, until at last this engineering defect was discovered during the investigation of an outbreak of postoperative tetanus. What do we rate as significant: the seven years in a paradise of ignorance or the one catastrophe? I know of a sterilizer which never revealed its defect until, challenged by unbleached cotton wool, which was suddenly introduced as a war economy measure, it demonstrably failed to kill the tetanus spores in the cotton wool in its lower third. Moreover, on further tests, it also failed to kill staphylococci in the same area. These facts about this particular sterilizer were discovered only after the majority of the patients of one morning's list had developed post-operative tetanus. Its discharge channel was ineffective. I know of another sterilizer which did not produce any disturbance in the minds of those who relied on it although dressings that came out of it were contaminated with a variety of organisms during the drying process. The contaminants found were mostly aerobic Gram-positive sporing bacilli and micrococci but at different times they also included Clostridium welchii and Staphylococcus aureus, organisms not present in the dressings before sterilization, so that a witty medical student said of the apparatus: 'Not perhaps much of a sterilizer-but a fertilizer!' Such tales are typical of those that abound wherever people meet who are concerned with autoclaves; and they are not the mere imaginings of enthusiasts, as is confirmed by the Nuffield Report (1958) and by the writer of 'Any Old Iron' (1959). An inefficient autoclave may not reveal its failure in terms which cause clinical misgiving for many years. In that sense the evidence suggests that autoclaves may not be very important quantitatively as direct causes of hospital sepsis. In outbreaks of post-operative tetanus and gas gangrene, they should obviously receive more critical study than they have often had during the investigation of some such reported episodes. Because they kill one packet of test spores, there is 
no guarantee that they can do so in every kind of package in any part of the load or that they do not recontaminate sterilized dressings during the drying process, and what more efficient way is there of concentrating the bacterial contamination of hospital air in a situation where it will really matter than of drawing it through a defective filter into a set of surgical dressings? And if, as often, the defective sterilizer also soaks the dressings and this has upset the surgeon, will not the sterilizer attendant make certain that the airing process at least is thoroughly done? I know of sterilizers where the drying process habitually lasted an hour or longer, and of one in particular where the process of drying was completed by placing the autoclaved drums, with open ports, on top of a radiator. The surgeon's reaction to being given a wet dressing was more predictable than the patients' reaction to being treated with one that was not sterile. Lister, whose earliest concern was mainly with airborne microorganisms, much later acknowledged that he was then more worried by 'grosser forms of septic mischief.' Those who so naively presumed upon their understanding of the realities of hospital bacteriology as almost wholly to supplant Lister's antiseptic methods by their aseptic ritual were surely an unwitting source of septic mischief. We cannot measure how much. But need we? As the advisers of surgeons surely we can stand on the doctrine that asepsis is meaningless ritual, charged with hidden errors and unmeasured risks, unless all that is labelled and regarded as sterile carries a valid guarantee that it is indeed free from microorganisms. It is true that some apparatus need not be sterile, cytoscopes, for example (Francis, 1959), and deliberate decisions merely to decontaminate certain articles may be accepted by those responsible provided they know exactly what they are doing. But for all that, the great majority of articles used in surgery can and should be sterile; and the instrument most relied upon to effect this sterilization is the autoclave. Therefore we must see to it that our surgeons' autoclaves are effective in their design and use.

\section{WHO IS RESPONSIBLE?}

The surgeon is a busy man, skilled in his particular and difficult duties, but he has not the outlook or experience of autoclaves possessed by a mechanical engineer, a pharmacist, or a bacteriologist. Reasonably, he looks for someone to see to the sterilization of his dressings and instruments. Often the theatre sister accepts this responsibility. But what does she know from her training of the working and maintenance of all the different varieties and makes of autoclaves? As much, probably, as a railway guard knows about the locomotive that pulls his train.
Sister will faithfully do what she has been taught, but autoclaves differ from each other in important details $\vec{\Rightarrow}$ and sisters move around. Theatre superintendents, $\stackrel{\vec{\rho}}{\stackrel{\rho}{9}}$ hospital porters, and relatively junior nurses mayo also operate autoclaves after receiving only the $\underline{\underline{D}}$ minimum of instruction. Often, as accidents to such $\frac{\bar{\rho}}{\bar{T}}$ operators have revealed, they know very little about $\stackrel{\mathbb{\Omega}}{\Omega}$ the true nature of the engineering considerations that $\$$ govern the correct use of steam under pressure. If the $\vec{\oplus}$ engineer, usually an overworked person, is called to? a faulty sterilizer he may well be content to repair $\vec{\omega}$ obvious defects and leave it at that. If he has to maintain and service in one hospital several different makes of autoclave he will need a great variety of $\vec{A}$ spare parts; and if his well meant advice is not $\stackrel{-}{-}$ readily understood or willingly accepted he may be pardoned for feeling that the calorifiers for heating the hospital deserve more of his attention and skill 5 than the autoclaves; in any case the end product of ${ }_{\vec{c}}^{-}$ the autoclaves is not his direct concern and he is un- $\frac{N}{5}$ likely to be unduly worried about their deficiencies unless someone else shows real concern. If an autoclave 2 falls under suspicion, the bacteriologist is likely to be $\vec{\oplus}$ called in because he is supposed to know about spore tests and because his work depends on efficiently ${ }_{\square}$ functioning autoclaves. Unfortunately, the bacterio-O logist's own working experience of autoclaves may not guide him to give the right advice about the surgeons' autoclaves.

Bacteriologists rely on their autoclaves mainly to sterilize media, all of which are fluid during steriliza- $\overrightarrow{0}$ tion, and instruments. These are easily sterilized 3 because the nature of the load offers no serious obstruction to attainment of the steam temperature? throughout the autoclave and the articles within it.⿳亠丷厂 The simple pressure-cooker type of autoclave is: readily able to meet the bacteriologist's needs, and 3 . the danger is that he may fail to realize how differento his instrument is from that required to steam and dry a load of packaged fabrics and other goodso required for use in an operating theatre or ward Until recent reports became required reading foro hospital bacteriologists, many of them revealed their unawareness of the true mode of action of theos surgical autoclave both by the advice they offeredr and by the over-simple and essentially unsatisfactoryn tests which they advised to check the functioning of surgeons' autoclaves.

Consequently, we may be forced to conclude tha? one of the principal needs for efficient autoclaving is? that some member of the medical staff both educates himself about autoclaves and undertakes the responsibility of being answerable to his medica $\vec{D}^{+}$ colleagues on two issues: (1) that adequate methods and apparatus are employed and are under the day $\Omega$ to-day care of a person of sufficient professionak 
standing to guarantee the faithful and exact performance of what is laid down; and (2) that regular checks of various kinds are applied, recorded, inspected, understood, and acted upon. Both the Nuffield Report (1958) and the first M.R.C. Report (1959) laid great emphasis on the need to define responsibility in this way.

\section{CENTRALIZED AUTOCLAVING}

Obviously both the medical man accepting such responsibilities and the day-to-day superviser can discharge their tasks only if the autoclaves in their charge are not too widely dispersed in many places. In practice this means that operating theatres will rely upon a central source to supply their sterile packaged goods but will have their own autoclaves for unwrapped instruments and bowls. Instruments and bowls are easily and quickly sterilized in a very simple type of autoclave (M.R.C. Reports, 1959 and 1960), which may yet be further simplified by the outcome of experiments still in progress. Such instruments may confidently be left to sisters and nurses, especially if their practical training and examination can be made to include the working of this particular piece of apparatus. Bottled fluids will probably remain in the charge of the pharmacist, and here again there is no reason to anticipate difficulty, both because the problems are fundamentally straightforward and because the training and examination of pharmacists lays considerable emphasis on the correct performance of sterilizing techniques. Current experiments with new designs of autoclaves for bottled fluids may be expected still further to increase the security of this particular sterilization process. Surgical dressings and other packaged goods, including rubber gloves, thus become the main problem of the centralized autoclaving unit, and it is to this that the rest of this article will be directed. The problems of centralization and of guaranteed performance have been simplified in the last few years out of all recognition by the introduction of highvacuum autoclaves with automatic controls. The enhanced capacity of such apparatus was clearly demonstrated by Wells and Whitwell (1960).

\section{REQUIREMENTS FOR SURE AND SAFE AUTOCLAVING}

A GOOD STEAM SUPPLY To guarantee the rapid killing of resistant spores, especially in textiles, it is necessary to have a reliable supply of steam under increased pressure at a temperature of from 121 to $134^{\circ} \mathrm{C}$. $\left(250-274^{\circ} \mathrm{F}\right.$.). If this steam is what is technically known to engineers as 'just dry' it will condense and penetrate rapidly with lethal effect into the substance of even the most resistant spores and it will not do more than merely dampen the dressings. However the steam is produced, direct from the mains or generated in apparatus near to or actually part of the autoclave, it must be dry and without more than $5^{\circ} \mathrm{C}$. of superheat. Commonly, from inadequate lagging and trapping, hospital mains steam supplied to autoclaves carries more than $10 \%$ of its weight made up of liquid water and such steam is unacceptable. Its improvement is essentially an engineering problem. Fitting adequate separators near to the sterilizer is of great value, but it must be emphasized that a reliable supply of steam is the first necessity for efficient autoclaving, of which the criteria are the regular and rapid production of dressings that are both sterile and dry.

REMOVAL OF AIR All parts of a load of textiles to be sterilized must be freed of air so that the load may be permeated by the steam. Autoclaves of the pressure cooker type make no provision for the removal of air during sterilization; hence they are unable to sterilize textiles. Until comparatively recently, this important matter was not widely understood by many who operated sterilizers in this country, and some do not yet appear to have grasped the point. There is little to be gained from the commonly used practice of employing steam-eje'tor mechanisms to draw a vacuum, or even two vacuums, of the order of $15 \mathrm{in} . \mathrm{Hg}$ or less. These low-order vacuums waste a great deal of steam and time and add to the damage to sensitive fabrics, such as rubber gloves. They remove some free air from between packages but they do not guarantee the almost instantaneous penetration of steam into all parts of the load of dressings. Although low-order vacuums could clearly help in marginal conditions, they are not to be recommended in practice. Air should be removed from the dressings either by its gradual displacement by steam or by drawing a high-order vacuum, that is, a vacuum greater than $29 \cdot 2$ in. $\mathrm{Hg}$. The small amount of air remaining in a load subjected to such a vacuum must be displaced by steam during sterilization to ensure that all parts of the textiles are sterilized. Simple displacement (also known as gravity-displacement or downward-displacement) sterilizers can be very efficient, but only if they are operated with a degree of skill and care which cannot by any evidence of recent experience be ascribed to the general group of people entrusted in this country with the operation of surgeons' autoclaves. For success, a steam supply of the right quality (see above) must be used upon a load lightly packed and properly positioned in a sterilizer fitted with a reliable automatic discharge mechanism with an adequate near-to-steam trap. The quality of the 
steam is checked, to some extent at least, by ascertaining if a thermometer placed in the discharge line gives a temperature reading corresponding to the pressure.

CORRECT LOADING AND EXPOSURE The loading of autoclaves is often done in such a way as to guarantee that, by steam displacement alone, all the air cannot be removed. Packs are more easily penetrated than drums, but they call for more careful storage. Cardboard boxes have certain attractions; they appear to be more easily penetrated by steam in high-vacuum autoclaves than are drums of the kind generally employed in hospitals; conversely they are rather less satisfactory in this respect in simple displacement autoclaves. Packs have much to commend them if the needs for their safe storage can be met (see M.R.C. Report, 1959): they have to be protected from dust, damp, and insects. Specially made metal caskets with built-in filters have a high initial cost but many advantages which, in the long run, may prove them to be the best form of container. Very large packs or drums or tightly packed loads will defeat steam penetration unless a vacuum of the order of $29.2 \mathrm{in}$. $\mathrm{Hg}$ can be drawn before steam is admitted. It is hardly realized how difficult it is to get steam through the loads commonly put into sterilizers. This, perhaps more than anything else, is where imperfectly trained and inexperienced operators fail in their understanding. High-vacuum sterilizers are justified because they overcome this problem and enable so great a shortening of the sterilizing cycle that few autoclaves are needed (Wells and Whitwell, 1960) and the temptations to overpacking are reduced. Likewise if fewer autoclaves are needed it is easier to centralize them under the control of a relatively small number of more skilled attendants. Those who have to deal with old sterilizers need not necessarily regard their task as hopeless. Some old sterilizers can be put into a state of reasonable efficiency (for details see Scott, 1957) without too much trouble and may be worked satisfactorily if enough skill can be devoted to them. It is with such autoclaves that care in packing and positioning is specially important. Without this, such sterilizers offer a poor guarantee of efficiency. Some downward-displacement autoclaves may be successfully upgraded to high-vacuum status either by local engineering modifications (Magee and Oakes, 1958) or by fitting conversion units which also provide automatic control (Alder and Gillespie, 1959). Such upgradings and conversions should not be embarked upon without first consulting the makers and the insurers of the sterilizer concerned.

Times of exposure for a properly packed load have been much discussed and debated. What will serve as a minimum, e.g., for unwrapped instruments, willo not be enough for fabrics in packs or dressing drums. $\Rightarrow$ The M.R.C. Report (1959), which gave a reasoned $\stackrel{5}{+}$ statement, recommend the following times and temperatures as a minimum exposure after the steam $\frac{\bar{\sigma}}{\overline{\underline{N}}}$. had reached the correct temperature for the pressure $\frac{\bar{\sigma}}{\sigma}$ employed:

$3 \mathrm{~min}$. at $134^{\circ} \mathrm{C}$. (30 lb. per sq. in.)

$10 \mathrm{~min}$. at $126^{\circ} \mathrm{C}$. (20 lb. per sq. in.)

$15 \mathrm{~min}$. at $121^{\circ} \mathrm{C}$. (15 lb. per sq. in.)

This short period of $3 \mathrm{~min}$. at $134^{\circ} \mathrm{C}$. is applicable $\vec{\omega}$ only to high-vacuum, high-pressure sterilizers which S are efficiently maintained and serviced and so fully용 controlled that any failure of the mechanics of $\vec{A}$ sterilization is made clear by appropriate warnings to the operator. These sterilizers obviously allow a $\overrightarrow{0}$ very short time margin to cover any error, and fullo attainment of the right conditions at every stage $?$ must therefore be automatically monitored and all $\bar{c}_{\bar{c}}$ failures made evident. If downward displacement is used for removal of air, and if the fabrics are correctly packed and loaded into a fully efficient 2 sterilizer, the M.R.C. Report (1959) recommended $\vec{\bullet}$ and gave reasons for the following for temperatures $\stackrel{\circ}{\rightarrow}$ of 121 and $126^{\circ} \mathrm{C}$.

\begin{tabular}{lcc} 
& $\begin{array}{l}\min . \text { at } 121^{\circ} \mathrm{C} . \\
(15 \mathrm{lb} . \text { per sq. in. })\end{array}$ & $\begin{array}{c}\min . \text { at } 126^{\circ} \mathrm{C} . \\
(20 \mathrm{lb} . \text { per } \text { sq. } \text { in. })\end{array}$ \\
\hline Instruments and utensils & 15 & 10 \\
Fabric packs & 30 & 20 \\
Dressing drums & 45 & 30
\end{tabular}

With high-vacuum equipment used under ideal conditions the complete cycle may be accomplished in 20 minutes or less. Obviously each sterilizer manufacturer ought to be consulted and the actual per-옹 formance of any new sterilizer installed should be critically checked by a competent engineer and 3 bacteriologist to ensure that whatever is laid down for the particular sterilizer is correctly decided.

Gloves and Glove Powder One point that needs 응 to be emphasized is that gloves should not be sterilized at low pressures, for example, at 10,7 , or even $5 \mathrm{lb}$. per square inch. If properly packed and not over-dried, gloves may be sterilized in the same $O$ way as other materials without being damaged. Im- $N$ perfectly sterilized gloves are a serious danger N especially if, as all too often, they are treated with ${ }_{\sigma}$ glove powder, which has not been correctly sterilized. If glass jars of glove powder with screwed-down lids are put into autoclaves, it may be asserted that $\stackrel{\oplus}{+}$ sterilization of the contents is impossible. Glove powder in small packets of guaranteed sterility is available commercially, or the powder may be $\stackrel{\odot}{\mathbb{D}}$ spread out flat on trays and baked in a hot-air oven $\frac{\text { }}{\mathbb{D}}$ at $160^{\circ} \mathrm{C}$. for one hour and carefully filled, with $\varrho$ sterile precautions, into small packets whose outside 
may be sterilized in the autoclave. Steam does not sterilize talcum powder because this substance is unwettable.

DRYING WITHOUT RECONTAMINATION Autoclaved dressings are often dried by drawing warm filtered air through them for periods that appear to range from 18 minutes to several hours. With the filtration methods hitherto commonly employed, or even in the absence of any filtering mechanism, which is not a rare situation, it is difficult or impossible to ensure the sterility of the warmed air (around $56^{\circ} \mathrm{C}$.) which is drawn into the sterilizer and may be passed without further ado directly through the open ports of unlined drums straight into the dressings. Various types of filters made of cottonwool or other fabrics have served well enough if conscientiously changed and correctly fitted. Rice (1960) designed a filtration set-up for autoclaves which greatly improved the prospects for efficient use of cottonwool filters. Work recently reported to the M.R.C. Working Party (M.R.C. Report, 1960) now suggests that glass fibre woven into sheet form of paper thickness offers the best prospects of a reliable filter which will stand up to autoclave conditions and have a working life of at least 12 months. The glass-fibre filter requires the support of metal grills to prevent distortion and it must be set in a well-made metal canister. A critical orifice is required to ensure uniformity of flow and prevent excessive strain on the filter. Apparatus of this kind is now available from at least two manufacturers in this country. ${ }^{1}$ Such filters should be highly efficient with a methylene-blue penetration of not more than $0.003 \%$.

An important aspect of the problem of drying without recontamination is to make sure that the dressings are dry at the outset, to use dry steam, and to draw a vacuum of $28 \mathrm{in}$. $\mathrm{Hg}$ after sterilization. If this vacuum is drawn (it need not be held for even five minutes) and if filtered air is then used to break the vacuum, nothing more should be required. If the dressings are still wet after such treatment, an engineering fault needs to be found and treated.

\section{TESTING AUTOCLAVES}

Full comprehension of all the details of the principles and practice of pressure-steam sterilization is not normally to be expected of the bacteriologist, who will be well advised, before tackling any autoclave about whose performance he is consulted, to insist that it should first be checked by an engineer who knows the apparatus and its function and can demonstrate the steam circuit of the particular auto-

1 (1) E. N. Mackley \& Co., Hawks Road, Gateshead 8, Co. Durham. (2) Vokes Ltd., Henley Park, Guildford, Surrey. clave. Such details of this kind as a bacteriologist may require to know are emphasized and summarized in the two M.R.C. Reports $(1959 ; 1960)$. When he is satisfied that the apparatus is accepted as in working order by the engineer, the bacteriologist should inspect the recent records of temperature and pressure which ought to be made for every sterilizing cycle and kept for inspection. The regular inspection of such records by someone who knows what they mean is itself probably the best single test of any autoclave. Too often such records are made but not examined by anyone who feels responsible for action if they reveal some failure of the autoclave. It would be a good custom if it came to be that every record were signed by a responsible member of the medical staff as well as by the sterilization attendant. A properly designed and correctly instrumented autoclave thus tests itself and makes its own record. In the past, no doubt, the form of such records has often been very hard to understand and their form has often been meaningless because they did not always record the steam temperature independently of the pressure. A temperature recording instrument with its sensitive end in the discharge line is essential, as well as a direct easily read thermometer. Recordings made from a dummy load in the lowest part of the sterilizer are an even better indication of performance. For special checks of the temperature attained in different parts of the sterilizer, directreading portable thermocouples are available. This type of apparatus enormously enhances the ease with which faults may be quickly detected and localized.

Routine bacteriological checks with spores of various kinds have been the subject of much confused thinking by bacteriologists and others. In many cases these tests have become as meaningless a ritual as other forms of inadequate operation of autoclaves. Such tests are no substitute for correct records of autoclave performance and scarcely necessary if these are properly kept and studied. As Kelsey (1958) established, many unsuitable spores have been employed, and intelligent use of chemical indicators has many advantages. Brown and Ridout (1960) made a careful and critical study of the ways of using such indicators and showed both their possibilities and limitations. In the past, it is clear that many tests, both with spores and chemical indicators, have been little more than an act of self-deception and have been welcomed mainly because they offered an impressive and apparently simple alternative to making sure that the autoclave was really able to do what was required of it. In checking new sterilizing methods and types of sterilizer, in making sure that recommended times and temperatures are sufficient, in devising new types of packaging, and in reassuring those conditioned to accepting only bacteriological 
checks, well-standardized preparations of bacterial spores have certainly a place. Kelsey (1961) has produced valuable information about the effective use and standardization of Bacillus stearothermophilus spores for this kind of work. Suitable spore preparations, if strategically placed in various critical positions in a sterilizer, give useful additional evidence and corroboration of the results of other tests; but nothing valuable is established by culturing routinely a single preparation of spores of uncertain standard placed wherever the sterilizer attendant cares to put it. A drum containing a few sterilized swabs placed near the air filter inlet may usefully be employed to check the efficiency of the air filter (Howie and Timbury, 1956). In spite of these generally critical observations, a few well-sited Browne's tubes (type II for high-vacuum, high-pressure sterilizers; type I for downward-displacement sterilizers) often give early warning to a conscientious theatre sister that her dressings have not been adequately exposed and that the autoclave needs a thorough investigation. The bacteriologist with his spores should come in only to test new methods and as a reassurance when required, for example, after an autoclave has been found inefficient and has been repaired. In short, it is not by some simple laboratory test that the bacteriologist will best serve the cause of efficient autoclaving and sterilization processes generally. He can discharge his professional duty in this matter, however, if he keeps himself up to date with new work on the subject, assesses it critically in relation to the problems of his own clinical colleagues, accepts medical responsibility for the work of the sterilizing department if this is so arranged as to make medical supervision a possible reality, and conducts a continuous process of education both for those who operate autoclaves and for those whose work depends on the guarantee of sterility which these instruments are intended to provide. If he can do all this and remain a good-humoured colleague he will indeed be entitled to regard himself as a worthy follower in the succession which includes Lister and Colebrook, in $\underline{\underline{\sigma}}$ honour of whose work this article was written.

\section{CONCLUSIONS}

This article reviews much of the recent work which $\stackrel{\nabla}{\overparen{D}}$ has shown that surgeons' autoclaves have been too readily accepted as reliable and efficient.

The main principles governing the successful $\vec{\circ}$ operation of autoclaves are briefly stated with $\overrightarrow{\vec{\omega}}$ references to published works in which the necessary $\stackrel{\omega}{\sigma}$ matters of detail are fully set forth.

As new types of autoclaves come into use, and

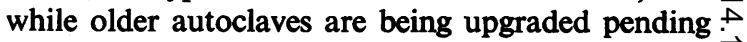
re-equipment and the general establishment of $\vec{s}$ centralized autoclaving, bacteriologists have an exacting duty to perform in gaining a full under- $\frac{}{3}$ standing of how surgeons' autoclaves work and of exercising a general function of education and supervision.

\section{REFERENCES}

Alder, V. G., and Gillespie, W. A. (1957). J. clin. Path., 10, 299.

(1959). Report published by The Drayton Regulator \& Instrument Co. Ltd., West Drayton, Middlesex.

'Any Old Iron.' (1959). Lancet, 2, 178.

Bowie, J. H. (1955). Pharm. J., 174, 473 and 489.

- (1958a). Hlth Bull. (Edinb.), 16, 36.

(1958b). Hosp. Engr., 12, 158 and 182.

Brown, W. R. L., and Ridout, C. W. (1960). Pharm. J., 184, 5.

Francis, A. E. (1959). Proc. roy. Soc. Med., 52, 998.

Howie, J. W., and Timbury, M. C. (1956). Lancet, 2, 669.

Kelsey, J. C. (1958). lbid., 1, 306.

-. (1961). J. clin. Path., 14, 59.

Knox, R., and Penikett, E. J. K. (1958). Brit. med. J., 1, 680.

Magee, K. C., and Oakes, H. E. (1958). Hosp. Engr., 12, 278.

Medical Research Council Report. (1959). Lancet, 1, 425. (1960). Ibid., 2, 1243.

Nuffield Provincial Hospitals Trust (1958). The Planning and $\bar{\partial}$ Organization of Central Syringe Services.

Penikett, E. J. K., Rowe, T. W., and Robson, E. (1958). J. appl. Bact., 21, 282.

Rice, H. M. (1958). Lancet, 2, 1275.

(1960). Ibid., 1, 960.

Scott, A. C. (1957). Ibid., 2, 633.

Wells, C., and Whitwell, F. R. (1960). Ibid., 2, 643. 